\title{
Efeitos da substituição do cimento Portland por escória de aciaria BSSF nas propriedades físicas e mecânicas do concreto
}

\author{
Effect of Portland cement replacement by BSSF \\ steel slag in the physical and mechanical \\ properties of concrete
}

\begin{abstract}
Alisson Rodrigues de Oliveira Dias ${ }^{1}$, Felipe Alves Amancio ${ }^{1}$, Isa Lauren Ximenes de Sousa ${ }^{2}$, Sarah Oliveira Lucas ${ }^{2}$, Douglas Alexandre Lima ${ }^{2}$, Antônio Eduardo Bezerra Cabral ${ }^{1}$
\end{abstract}

\footnotetext{
${ }^{1}$ Programa de Pós-Graduação em Engenharia Civil - Estruturas e Construção Civil - PEC/UFC, Universidade Federal do Ceará, CEP: 60455-900, Fortaleza, CE, Brasil.

${ }^{2}$ Departamento de Estruturas e Construção Civil, Universidade Federal do Ceará, CEP: 60455-900, Fortaleza, CE, Brasil. e-mail: rodrigues_alisson@live.com, felipeaamancio@hotmail.com, eduardo.cabral@ufc.br, isalaurenengenharia@gmail.com, saraholiveiraluks@gmail.com,douglas.edif@gmail.com
}

\section{RESUMO}

O presente estudo teve por objetivo investigar as propriedades físicas e mecânicas do concreto com a utilização dos finos da escória de aciaria BSSF em substituição parcial ao cimento Portland. O trabalho experimental contou com ensaios de caracterização físico-química da escória de aciaria BSSF, bem como caracterização das propriedades no estado fresco e endurecido dos concretos produzidos com a substituição de cimento por finos de escória de aciaria BSSF nos teores de 3\%, 6\% e 12\%. As propriedades analisadas foram: massa específica, teor de ar incorporado, consistência, resistência à compressão nas idades de 7, 28 e 63 dias, módulo de elasticidade, resistência à tração por compressão diametral, índice de vazios e absorção de água. Todos os dados coletados foram analisados estatisticamente, empregando-se a Análise de Variância (ANOVA) e teste de comparação de médias de Tukey. Com os resultados obtidos, pode-se constatar que no estado fresco, para a mesma consistência, os concretos apresentaram maior demanda de aditivo e maiores valores de massa específica. No estado endurecido, os concretos apresentaram melhorias significativas na resistência à compressão e módulo de elasticidade. Em relação à durabilidade, os concretos com maiores teores de substituição apresentaram os menores valores de absorção de água por imersão e índice de vazios.

Palavras-chave: Concreto. Escória de aciaria BSSF. Substituição do cimento.

\begin{abstract}
The present study aimed to investigate the physical and mechanical properties of concrete with use of BSSF steel slag fines in partial replacement to Portland cement. The experimental work consisted of physicalchemical characterization tests of BSSF steel slag, as well as characterization of the properties in the fresh and hardened concrete state produced by the replacement of cement by BSSF steel slag fines at $3 \%, 6 \%$ and $12 \%$. The properties analyzed were: specific mass, incorporated air content, consistency, compressive strength at the ages of 7,28 and 63 days, modulus of elasticity, tensile strength, voids index and water absorption. All data collected were statistically analyzed using Analysis of Variance (ANOVA) and Tukey test. With the obtained results, it can be seen that in the fresh state, the concretes presented higher additive demand for same consistency and higher values of specific mass. In the hardened state, concretes showed significant improvements in compressive strength and modulus of elasticity. Regarding durability, concretes with higher replacement contents presented the lowest values of water absorption by immersion and voids index
\end{abstract}

Keywords: Concrete. BSSF steel slag. Cement replacement. 


\section{INTRODUÇÃO}

A busca por sustentabilidade na construção civil é crescente, principalmente devido à grande quantidade de emissões de dióxido de carbono $\left(\mathrm{CO}_{2}\right)$ ocorridas durante a produção de cimento Portland. As emissões de gases de efeito estufa através de atividades industriais têm um grande impacto no aquecimento global. Acredita-se que pelo menos $5 \%$ a $7 \%$ do $\mathrm{CO}_{2}$ liberado à atmosfera ocorra devido à produção de cimento [1]. Isto torna a indústria do concreto uma importante fonte de emissões de $\mathrm{CO}_{2}$ [2].

A incorporação de resíduos na produção de compósitos cimentícios, em substituição ao cimento Portland, torna-se atrativa no intuito de reduzir custos e impactos ambientais [3-5], além de melhorar as propriedades dos mesmos. Essa aplicação de resíduos tem sido investigada em diversos estudos, dentre os principais tem-se destaque para as cinza volante [6,7], cinza de aterro sanitário [8], cinza do bagaço da cana de açucar [9], lodo de estação de tratamento de água [10, 11], escória granulada de alto forno [12], finos de materiais cerâmicos [13, 14], metacaulim [15], resíduos de pó de mármore [16-18].

Além disto, o uso de adições em concreto, como por exemplo os fíleres, ocasionam uma melhoria no empacotamento das partículas, e consequentemente melhoram suas propriedades no estado fresco e endurecido, bem como a sua microestrutura [19]. Entretanto, os materiais de baixa energia incorporada precisam apresentar desempenho tão bom quanto o dos materiais convencionais [20].

Aliado a isto, tem-se a grande geração de resíduos pelos processos industriais, como por exemplo a indústria siderúrgica. No ano de 2017, a produção mundial de aço bruto foi de aproximadamente 1,7 bilhão de toneladas. O Brasil se destacou como $9^{\circ}$ maior produtor mundial, tendo produzido cerca de 34,4 milhões de toneladas de aço bruto nesse mesmo ano, o que representa $2,1 \%$ da produção mundial. Já na América Latina, a supremacia foi brasileira, correspondendo a 53,5\% do total produzido no continente em 2017 [21].

Durante o processo de produção do aço, as indústrias siderúrgicas geram grandes quantidades de escória de aciaria como resíduo [22]. Em 2017, conforme o Relatório de Sustentabilidade mais recente, publicado pelo Instituto Aço Brasil, cada tonelada de aço produzida gera 607 quilogramas de coprodutos (escória de alto forno e escória de aciaria) e residuos (pós e lamas) [21]. Portanto, à medida que a produção de aço aumenta, a quantidade de resíduos gerados se torna um problema ambiental com grau de urgência de tratamento, sendo imperativo para as gerações futuras que estes materiais sejam considerados recursos para serem reutilizados [23, 24].

É possível encontrar na literatura diversas aplicações para a escória de aciaria, como por exemplo na produção de misturas asfálticas [25, 26], materiais cerâmicos [27] e ,principalmente, como agregado em materiais cimentícios [22, 28- 30]. Entretanto, o uso da escória de aciaria em materiais cimentícios ainda é pouco vantajosa por conta da possibilidade de ocorrência de expansões, causadas principalmente, pelo alto teor de óxido de cálcio $(\mathrm{CaO})$ e óxido de magnésio $(\mathrm{MgO})$ livres [31, 32].

O desenvolvimento de um novo tratamento para as escórias de aciaria, denominado Baosteel Slag Short Flow (BSSF) permitiu minimizar o efeito das reações expansivas de seus componentes e viabilizar a sua aplicação em materiais cimentícios. Nesse processo, a escória de aciaria ainda líquida é basculada em um tambor rotativo, sendo resfriada rapidamente com jatos de água controlados, combinado com forças mecânicas para trituração, formando um material de característica vítrea, granulado e com baixas quantidades de cal livre [14, 33, 34]. Como resultado desse processo tem-se a obtenção da escória de aciaria do tipo Baosteel Slag Short Flow - BSSF, objeto de estudo deste trabalho. No Ocidente, a Companhia Siderúrgica do Pecém - CSP, localizada no Estado do Ceará é a única empresa siderúrgica que incluiu esse processo na sua linha de produção do aço até o presente momento.

Neste sentido, nota-se a importância do aproveitamento de resíduos em materiais cimentícios, e principalmente do uso da escória de aciaria BSSF. Com isto, o presente trabalho tem como objetivo avaliar o efeito da substituição do cimento Portland por finos de escória de aciaria BSSF nas propriedades físicas e mecânicas do concreto.

\section{MATERIAIS E MÉTODOS}

\subsection{Materiais}

Nesta pesquisa foi utilizado cimento Portland CP V - ARI. As Tabelas 1 e 2 apresentam as características físicas e químicas do cimento fornecidas pelo fabricante. 
Tabela 1: Características físicas e químicas do cimento CP V - ARI utilizado.

\begin{tabular}{c|c|c|c}
\hline ENSAIO & NORMA & RESULTADO & $\begin{array}{c}\text { ESPECIFICAÇÃO - NORMA } \\
\text { ABNT NBR 16697/2018 }\end{array}$ \\
\hline Perda ao fogo & ABNT NM 18/12 & $4,39 \%$ & $\leq 6,5 \%$ \\
\hline Óxido de Magnésio $-\mathrm{MgO}$ & ABNT NM 11-2/12 & $4,17 \%$ & $\leq 6,5 \%$ \\
\hline Anidrido Sulfúrico $-\mathrm{SO}_{3}$ & ABNT NM 16/12 & $3,24 \%$ & $\leq 4,5 \%$ \\
\hline Resíduo Insolúvel & ABNT NM 15/12 & $0,69 \%$ & $\leq 3,5 \%$ \\
\hline Anidrido Carbônico $-\mathrm{CO}_{2}$ & ABNT NBR 11578/91 & $2,97 \%$ & $\leq 5,5 \%$ \\
\hline Massa específica & ABNT NM 23/01 & $3,06 \mathrm{~g} / \mathrm{cm}^{3}$ & Não aplicável \\
\hline Finura (\#200) & ABNT NBR 11579/12 & $0,20 \%$ & $\leq 6,0 \%$ \\
\hline Início de pega & ABNT NM 65/03 & $2: 15 \mathrm{~h}: \mathrm{min}$ & $\leq 10: 00 \mathrm{~h}: \mathrm{min}$ \\
\hline Fim de pega & ABNT NM 65/03 & $3: 45 \mathrm{~h}: \mathrm{min}$ & $\leq 5: 00 \mathrm{~h}: \mathrm{min}$ \\
\hline Expansibilidade a quente & ABNT NBR 11582/16 & $0,00 \mathrm{~mm}$ & $\leq 6,5 \mathrm{~mm}$ \\
\hline
\end{tabular}

Tabela 2: Resistência à compressão em MPa do cimento CP V - ARI utilizado.

\begin{tabular}{c|c|c}
\hline IDADE (DIAS) & MÉDIA (MPA) & $\begin{array}{c}\text { ESPECIFICAÇÃO - NORMA } \\
\text { ABNT NBR 16697/2018 }\end{array}$ \\
\hline 1 & 25,9 & $\geq 14,0 \mathrm{MPa}$ \\
\hline 3 & 36,6 & $\geq 24,0 \mathrm{MPa}$ \\
\hline 7 & 44,3 & $\geq 34,0 \mathrm{MPa}$ \\
\hline 28 & 53,2 & - \\
\hline
\end{tabular}

A água utilizada atendeu aos requisitos da ABNT NBR 15900 [35]. O aditivo foi do tipo superplastificante da linha MasterGlenium ACE 402, composto por carboxilatos. O aditivo possuía pH 7, densidade de $1,15 \mathrm{~g} / \mathrm{cm}^{3}$ e solubilidade em água de $100 \mathrm{~g} / \mathrm{L}$. Os agregados utilizados foram provenientes da Região Metropolitana de Fortaleza - Ceará e atenderam aos requisitos da ABNT NBR 7211 [36]. Foi utilizado brita de origem granítica como agregado graúdo e areia grossa, extraída de rio, lavada e peneirada como agregado miúdo. A Tabela 3 apresenta as propriedades físicas dos agregados utilizados.

Tabela 3: Propriedades físicas dos agregados.

\begin{tabular}{c|c|c|c|c}
\hline \multirow{2}{*}{ ENSAIO } & \multirow{2}{*}{ UNIDADE } & \multicolumn{3}{|c}{ AGREGADO } \\
\cline { 3 - 5 } & & AREIA & $\begin{array}{c}\text { BRITA } \\
\mathbf{1 2 , 5} \mathbf{~ m m}\end{array}$ & $\begin{array}{c}\text { BRITA } \\
\mathbf{1 9} \mathbf{~ m m}\end{array}$ \\
\hline Diâmetro máximo característico & $\mathrm{mm}$ & 4,75 & 12,5 & 19,0 \\
\hline Módulo de finura & Adimensional & 2,65 & 5,99 & 6,84 \\
\hline Massa unitária & $\mathrm{g} / \mathrm{cm}^{3}$ & 1,41 & 1,41 & 1,37 \\
\hline Absorção de água & $\%$ & 0,90 & 0,89 & 0,94 \\
\hline Massa específica & $\mathrm{g} / \mathrm{cm}^{3}$ & 2,59 & 2,61 & 2,61 \\
\hline Material pulverulento & $\%$ & 1,00 & 0,29 & 0,90 \\
\hline
\end{tabular}

A escória de aciaria BSSF utilizada foi gerada pela Companhia Siderúrgica do Pecém, localizada no estado do Ceará. $\mathrm{O}$ material foi seco em estufa $\left(105 \pm 5^{\circ} \mathrm{C}\right)$ até a constância de massa. Em seguida foi realizado o peneiramento, tendo sido utilizado o material passante na peneira de série normal de abertura de $0,075 \mathrm{~mm}$. A massa específica da escória de aciaria BSSF é de $3,72 \mathrm{~g} / \mathrm{cm}^{3}$, determinada conforme ABNT NBR 16605 [37]. A caracterização química da escória de aciaria BSSF foi determinada através do ensaio de Fluorescência de Raios X (FRX) no Laboratório de Raios X, do Departamento de Física da Universidade Federal do Ceará - UFC e pode ser observada na Tabela 4. Os resultados obtidos mostram que a escória de aciaria BSSF é constituída basicamente de $\mathrm{Fe}_{2} \mathrm{O}_{3}, \mathrm{CaO}$ e $\mathrm{SiO}_{2}( \pm 92 \%)$. 
Tabela 4: Composição química da escória de aciaria BSSF determinada através do ensaio de FRX.

\begin{tabular}{l|l|l|l|l|l|l|l|l|l|l}
\hline òXIDOS & $\mathrm{Al}_{2} \mathrm{O}_{3}$ & $\mathrm{SiO}_{2}$ & $\mathrm{P}_{2} \mathrm{O}_{5}$ & $\mathrm{~K}_{2} \mathrm{O}$ & $\mathrm{CaO}$ & $\mathrm{TiO}_{2}$ & $\mathrm{Cr}_{2} \mathrm{O}_{3}$ & $\mathrm{MnO}$ & $\mathrm{Fe}_{2} \mathrm{O}_{3}$ & $\mathrm{Co}_{2} \mathrm{O}_{3}$ \\
\hline AMOSTRA (\%) & 0,63 & 5,84 & 1,01 & 0,04 & 33,46 & 0,63 & 0,21 & 5,09 & 52,98 & 0,12 \\
\hline
\end{tabular}

No que se refere à composição mineralógica da escória de aciaria BSSF, esta foi analisada por meio do ensaio de Difração de Raios X, realizado no Laboratório de Raios X do Departamento de Física da Universidade Federal do Ceará - UFC. O equipamento utilizado foi o difratômetro para amostras policristalinas modelo Xpert Pro MPD Panalytical. Nesse ensaio foi possível identificar principalmente, a presença das fases cristalinas de wustita $(\mathrm{FeO})$ e magnetita $\left(\mathrm{Fe}_{3} \mathrm{O}_{4}\right)$. A escória de aciaria BSSF não possui uma estrutura cristalina definida, resultado do processo de resfriamento rápido que não fornece o tempo e as condições adequadas para a formação das fases cristalinas, sendo caracterizada como um material amorfo. As fases que melhor caracterizavam os picos foram também as de maior quantidade e estão apresentadas no difratograma exposto na Figura 1.

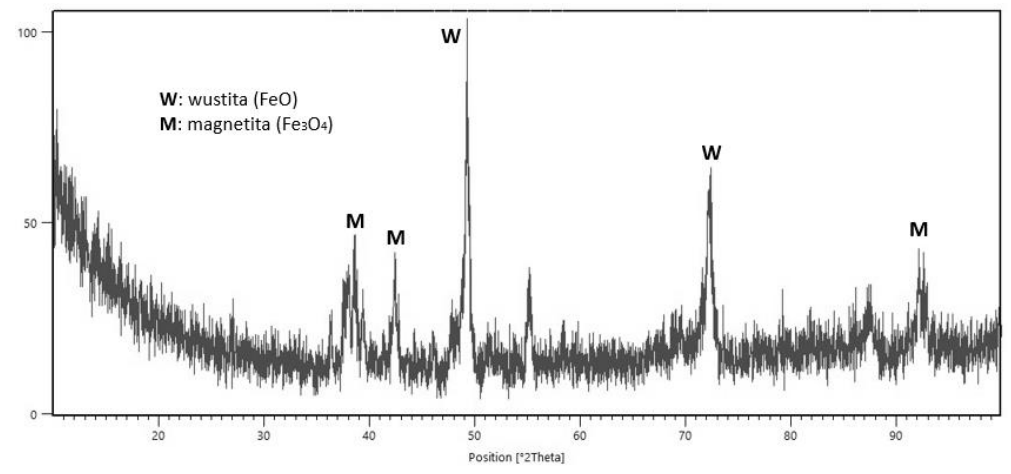

Figura 1: Difratograma da escória de aciaria BSSF.

Foi investigado ainda o fenômeno da expansibilidade da escória de aciaria BSSF por meio da ABNT NBR 16697 [38]. O ensaio foi realizado com base na determinação da expansibilidade do cimento pelo método de Le Chatelier [39], no Laboratório de Materiais de Construção Civil - LMCC da Universidade Federal do Ceará - UFC. Para esse método foi adotado um teor de substituição de cimento por escória de aciaria BSSF de 50\%, em volume. Para MEHTA e MONTEIRO [40], esse teor é suficiente para que o fenômeno ocorra, caso o material possua características expansivas. Destaca-se que a mesma não apresentou expansão a frio e em relação à expansão a quente, todos os resultados obtidos encontraram-se dentro do limite máximo especificado em norma de $5 \mathrm{~mm}$.

Para a obtenção da granulometria, foi realizada por meio da difração a laser, utilizando um analisador de partículas Mastersize 2000E (Malvern Instruments), com o auxílio de uma unidade de dispersão Scirocco 2000M. A distribuição das partículas é apresentada na Figura 2.

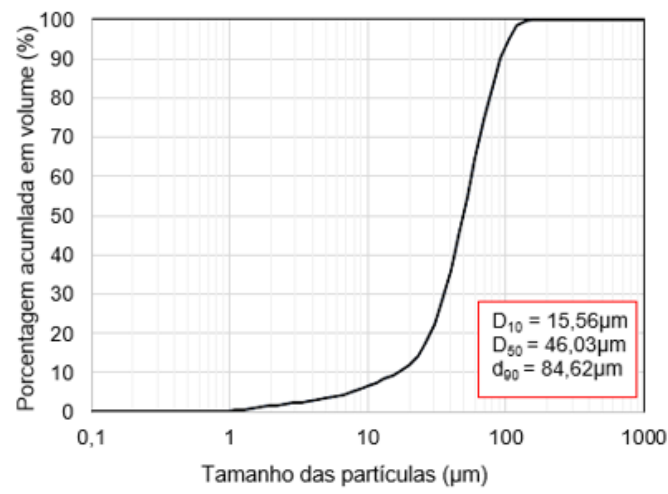

Figura 2: Granulometria a laser da escória de aciaria BSSF. 
Por fim, foi realizado ensaio de pozolanicidade da escória de aciaria BSSF com o cimento Portland aos 28 dias, conforme preconiza a norma ABNT NBR 5752 [41]. Foi determinado um índice de atividade pozolânica de $71 \%$, o qual, conforme a norma ABNT NBR 12653 [42] não caracteriza a escória de aciaria BSSF como material pozolânico, pois o valor obtido é inferior ao estabelecido (maior ou igual a 90\%).

\subsection{Métodos de pesquisa}

A fim de analisar o comportamento do concreto em relação a suas características mecânicas com a aplicação da escória de aciaria BSSF em substituição ao cimento Portland foram estudados traços produzidos com os teores de substituição, em volume, de 0\%, 3\%, 6\% e 12\% em concretos com classe de resistência de $30 \mathrm{MPa}$.

A consistência foi fixada em $(100 \pm 10) \mathrm{mm}$ realizado por meio do ensaio slump test, conforme a norma ABNT NBR NM 67 [43], sendo este corrigido por meio do aumento do teor de aditivo. A Tabela 5 apresenta o consumo de materiais por metro cúbico desses traços. Ressalta-se que a porcentagem de aditivo se refere somente à massa de cimento, visto que, apesar da escória de aciaria BSSF ter sido utilizada como material substituto ao cimento, a mesma não possui propriedades aglutinantes.

Tabela 5: Consumo de materiais $\left(\mathrm{em} \mathrm{kg} / \mathrm{m}^{3}\right)$ dos traços investigados.

\begin{tabular}{c|c|c|c|c|c|c|c|c}
\hline TRAÇO & $\begin{array}{c}\text { TEOR } \\
\text { SUBST. }\end{array}$ & CIMENTO & $\begin{array}{c}\text { ESCÓRIA DE } \\
\text { ACIARIA BSSF }\end{array}$ & AREIA & $\begin{array}{c}\text { BRITA } \\
\mathbf{1 2 , 5 M M}\end{array}$ & $\begin{array}{c}\text { BRITA } \\
\text { 19MM }\end{array}$ & $\begin{array}{c}\text { ADITIVO } \\
(\%)\end{array}$ & ÁGUA \\
\hline TREF & $0 \%$ & 360,0 & - & 794 & 264 & 703 & 0,28 & 180 \\
\hline TS3 & $3 \%$ & 349,2 & 13,1 & 794 & 264 & 703 & 0,29 & 180 \\
\hline TS6 & $6 \%$ & 338,4 & 26,3 & 794 & 264 & 703 & 0,34 & 180 \\
\hline TS12 & $12 \%$ & 316,8 & 52,6 & 794 & 264 & 703 & 0,41 & 180 \\
\hline
\end{tabular}

No estado fresco, o teor de ar incorporado foi determinado segundo as recomendações da ABNT NBR NM 47 [44] e em seguida determinou-se a massa específica no estado fresco, conforme preconiza a ABNT NBR 9833 [45]. Para a realização dos ensaios no estado endurecido, foram moldados corpos de prova cilíndricos com $20 \mathrm{~cm}$ de altura e $10 \mathrm{~cm}$ de diâmetro conforme os procedimentos da ABNT NBR 5738 [46]. Após a moldagem, os corpos de prova foram submetidos à cura úmida por imersão em tanques de água não corrente, à temperatura ambiente. $\mathrm{O}$ ensaio de compressão axial foi realizado de acordo com os procedimentos da ABNT NBR 5739 [47], nas idades de 7, 28 e 63 dias. O módulo de elasticidade foi realizado com a utilização de extensômetro eletrônico de base dupla, com dois sensores, dispostos em faces opostas do corpo de prova, seguindo os procedimentos da ABNT NBR 8522 [48], aos 28 dias de idade. Também foram avaliadas a resistência à tração por compressão diametral, segundo a ABNT NBR 7222 [49], além da determinação da absorção de água por imersão, índice de vazios e massa específica no estado endurecido, por meio do ensaio preconizado pela ABNT NBR 9778 [50], aos 28 dias. Para cada determinação desses ensaios foram utilizadas 3 amostras por traço, totalizando 18 corpos de prova por traço e 72 corpos de prova no total. Todos os ensaios foram realizados no Laboratório de Materiais de Construção Civil - LMCC da Universidade Federal do Ceará - UFC.

Por fim, a análise estatística dos resultados seguiu as etapas de identificação dos resíduos padronizados, eliminação dos dados espúrios, Análise de Variância (ANOVA), com um nível de confiança de $95 \%$ e teste de comparação múltipla (Teste de Tukey).

\section{RESULTADOS E DISCUSSÕES}

A Tabela 6 apresenta a caracterização dos concretos no estado fresco, com a substituição do cimento Portland por finos de escória de aciaria BSSF.

Tabela 6: Propriedades no estado fresco.

\begin{tabular}{c|c|c|c|c|c}
\hline TRAÇO & $\begin{array}{c}\text { SLUMP } \\
\text { TEST }\end{array}$ & $\begin{array}{c}\text { TEOR } \\
\text { SUBST. }\end{array}$ & TEOR DE ADITIVO & $\begin{array}{c}\text { TEOR DE AR } \\
\text { INCORPORADO }\end{array}$ & MASSA ESPECÍFICA \\
\hline TREF & $100 \mathrm{~mm}$ & $0 \%$ & $0,28 \%$ & $2,0 \%$ & $2,17 \mathrm{~g} / \mathrm{cm}^{3}$ \\
\hline $\mathrm{TS} 3$ & $105 \mathrm{~mm}$ & $3 \%$ & $0,29 \%$ & $4,0 \%$ & $2,21 \mathrm{~g} / \mathrm{cm}^{3}$ \\
\hline $\mathrm{TS} 6$ & $95 \mathrm{~mm}$ & $6 \%$ & $0,34 \%$ & $4,0 \%$ & $2,22 \mathrm{~g} / \mathrm{cm}^{3}$ \\
\hline $\mathrm{TS} 12$ & $95 \mathrm{~mm}$ & $12 \%$ & $0,41 \%$ & $4,0 \%$ & $2,26 \mathrm{~g} / \mathrm{cm}^{3}$ \\
\hline
\end{tabular}


Pode-se verificar na Tabela 6 que a substituição do cimento por finos de escória de aciaria BSSF ocasionou um aumento no consumo de aditivo, para que fosse possível manter a mesma consistência especificada na metodologia. Isto se deve ao aumento da área superficial a ser molhada (adsorvida), em virtude da adição de partículas finas de escória de aciaria BSSF, bem como sua absorção de água elevada. No mesmo sentido, WESTERHOLM e LAGERBLAD [51] explicam que a utilização de finos em concreto demanda uma maior quantidade de superplastificante para manter a consistência. Em adição, tem-se a influência da forma e textura dos grãos de escória de aciaria BSSF, pois escórias geradas pelo método de conversor básico à oxigênio, como é o caso da BSSF, comumente gera um agregado de formato angular com superfície áspera, permitindo um maior intertravamento entre si ou entre outros materiais [52, 53]. Em relação à massa específica, verifica-se que ocorreu um incremento com o aumento do teor de substituição. Isto se deve a massa específica da escória de aciaria BSSF ser cerca de $22 \%$ superior à massa específica do cimento utilizado.

Em relação às propriedades mecânicas, verificou-se que houve um incremento de resistência à compressão em todas as idades investigadas com a substituição do cimento por escória de aciaria BSSF (Figura 3-a). Na idade de 7 dias o acréscimo de resistência para o traço produzido com 12\% de escória de aciaria BSSF é de aproximadamente $28 \%$, quando comparado ao traço de referência. Os traços com teores de $3 \%$ e $6 \%$ alcançaram valores superiores na ordem de $12 \%$ e $15 \%$, respectivamente, para a mesma idade, em comparação ao traço de referência. Segundo Teste de Tukey, aos 28 dias de idade, os valores médios obtidos para os traços contendo os teores de $0 \%, 3 \%$ e $6 \%$ não diferem significativamente entre si, ou seja, a substituição de cimento Portland por escória de aciaria BSSF só é significativa a partir do teor de $12 \%$ para o desempenho de resistência à compressão do concreto, na idade citada. Em relação ao módulo de elasticidade, a substituição também ocasionou um acréscimo de 2,6\%,14,3\% e 12,5\%, respectivamente para os traços TS3, TS6 e TS12, em relação ao traço de referência, entretanto de forma menos acentuada (Figura 3-b). De acordo com o Teste de Tukey, esse aumento passa a ser significativo a partir do teor de substituição de $6 \%$, onde identificou-se um ganho na ordem de $14 \%$.

a)

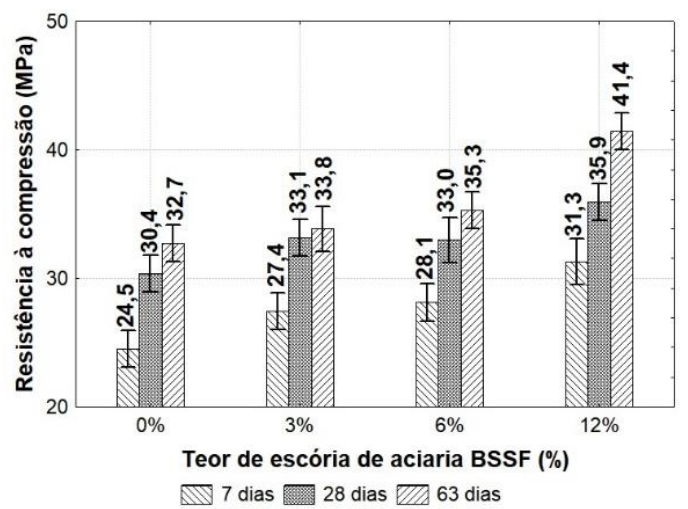

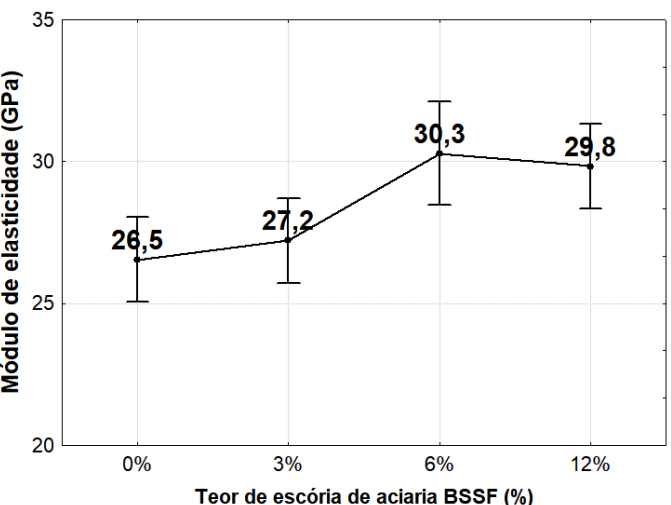

Figura 3: Efeito da substituição do cimento Portland por finos de escória de aciaria BSSF nas propriedades mecânicas: a) resistência à compressão (por idade) e; b) módulo de elasticidade do concreto (aos 28 dias).

É possível notar que com o aumento dos teores de substituição de cimento Portland por escória de aciaria BSSF há uma tendência em aumentar os valores de resistência à compressão e módulo de elasticidade. Isto se deve possivelmente devido ao melhor empacotamento dos grãos, em virtude dos microfinos, gerando assim um melhor preenchimento dos vazios no concreto, bem como à elevada massa específica e dureza da escória de aciaria BSSF. Visto que uma maior dureza e massa específica dos constituintes do concreto influenciam de modo benéfico essas propriedades [40]. Ademais, MOTZ e GEISELER [54] e LUXAN et al. [55] explicam que a dureza da escória de aciaria é similar ou superior aos agregados de origem quartzosa e granítica.

Destaca-se ainda a influência na resistência à compressão nos traços com maiores teores de escória de aciaria BSSF, em virtude do aumento do consumo de aditivo, ao passo que a adição de superplastificante no concreto tem efeito benéfico em suas propriedades, através da dispersão das partículas finas que o mesmo ocasiona, contribuindo para uma maior hidratação das partículas de cimento e permitindo um maior preenchimento dos vazios pelas partículas de escória de aciaria BSSF, promovendo assim, uma maior compacidade à mistura [19]. Quanto ao módulo de elasticidade, era previsível um incremento, tendo em vista 
que a resistência do concreto exerce influência no módulo de elasticidade $[40,56]$. No mesmo sentido, a ABNT NBR 6119 [57] estabelece equações visando estimar o módulo de elasticidade por meio da resistência à compressão de forma diretamente proporcional, de maneira que concretos com maiores valores de resistência, apresentem maiores valores de módulo de elasticidade. Assim ocorreu para os traços estudados.

Foi possível estabelecer uma correlação linear entre o teor de substituição com a resistência à compressão e o módulo de elasticidade, sendo determinados coeficientes de correlação $\left(\mathrm{R}^{2}\right)$ nos valores de 0,91 e 0,66 , respectivamente. Os valores de $\mathrm{R}^{2}$ indicam que o teor de substituição apresenta satisfatória relação com a resistência à compressão, porém uma menor relação com o módulo de elasticidade. Observando a Figura 4, nota-se que possivelmente a relação entre teor de substituição e módulo de elasticidade foi afetada negativamente pelo valor obtido no traço TS6 (teor de 6\% de substituição), entretanto, o teste de comparações de médias de Tukey mostrou que os valores obtidos para essa propriedade, entre os traços TS6 e TS12 não diferem significativamente entre si. Desta forma, para melhorar a correlação entre teor de substituição e módulo de elasticidade, seria necessário o ensaio com novos teores, superiores a $12 \%$.

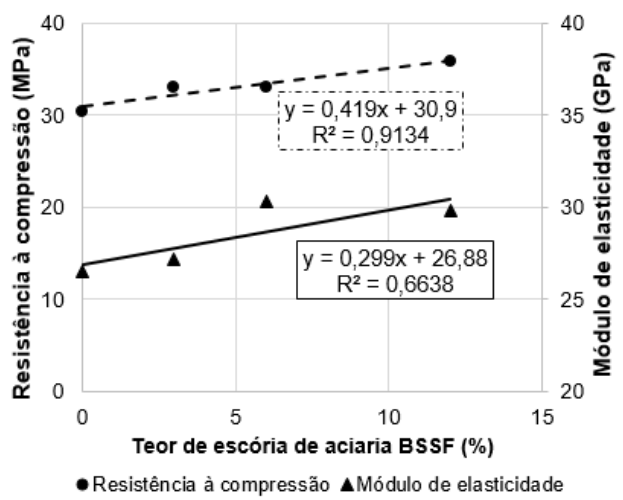

Figura 4: Correlação entre o teor de substituição de cimento por finos de escória de aciaria BSSF com a resistência à compressão e módulo de elasticidade.

Quanto à resistência à tração por compressão diametral, constatou-se por meio de ANOVA que a substituição do cimento Portland por escória de aciaria BSSF não exerceu influência significativa nesta propriedade. Para GONÇALVES e MARGARIDO [58] a zona de transição do concreto assume grande importância no ganho de resistência à tração. Portanto, apesar da incorporação de escória de aciaria BSSF ter ocasionado um acréscimo na resistência à compressão, essa se deu por conta do maior preenchimento de vazios, não gerando influências significativas na zona de transição do concreto, como consequência, os resultados obtidos para resistência à tração pelos traços produzidos com escória de aciaria BSSF obtiveram resultados significativamente similares ao obtido pelo traço de referência. Esses resultados podem ser visualizados na Figura 5.

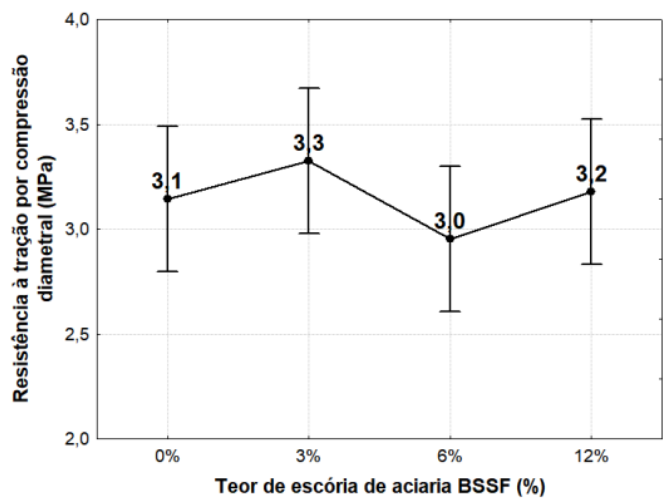

Figura 5: Resistência à tração por compressão diametral dos concretos conforme o teor de substituição de cimento por finos de escória de aciaria BSSF (aos 28 dias).

Em relação à massa específica dos concretos no estado endurecido, nota-se que ocorreu um aumento desta propriedade conforme aumenta-se o teor de substituição de cimento por escória de aciaria BSSF 
(Figura 6-a), atingindo um acréscimo máximo de $4 \%$ no traço com teor de $12 \%$ de substituição. Isto pode ser justificado pela elevada massa específica da escória de aciaria BSSF em relação ao cimento Portland. Com a realização da ANOVA verificou que a substituição do cimento por finos de escória de aciaria BSSF exerce influência significativa nesta propriedade. Entretanto, conforme a realização do teste de comparação de média de Tukey, verifica-se que não ocorre diferenças significativas entre o traço de referência e os traços com teores de substituição de $3 \%$ e $6 \%$, sendo considerados estatisticamente equivalentes.

Na Figura 6-b é apresentada a relação entre as massas específicas do concreto nos estados fresco (eixo x) e endurecido (eixo y), sendo possível observar que mesmo após a incorporação de escória de aciaria BSSF, essas continuaram a se correlacionar de maneira satisfatória, com um coeficiente de correlação $\left(\mathrm{R}^{2}\right)$ no valor de 0,91. Tal relação entre as massas específicas condiz com a literatura $[40,56]$.
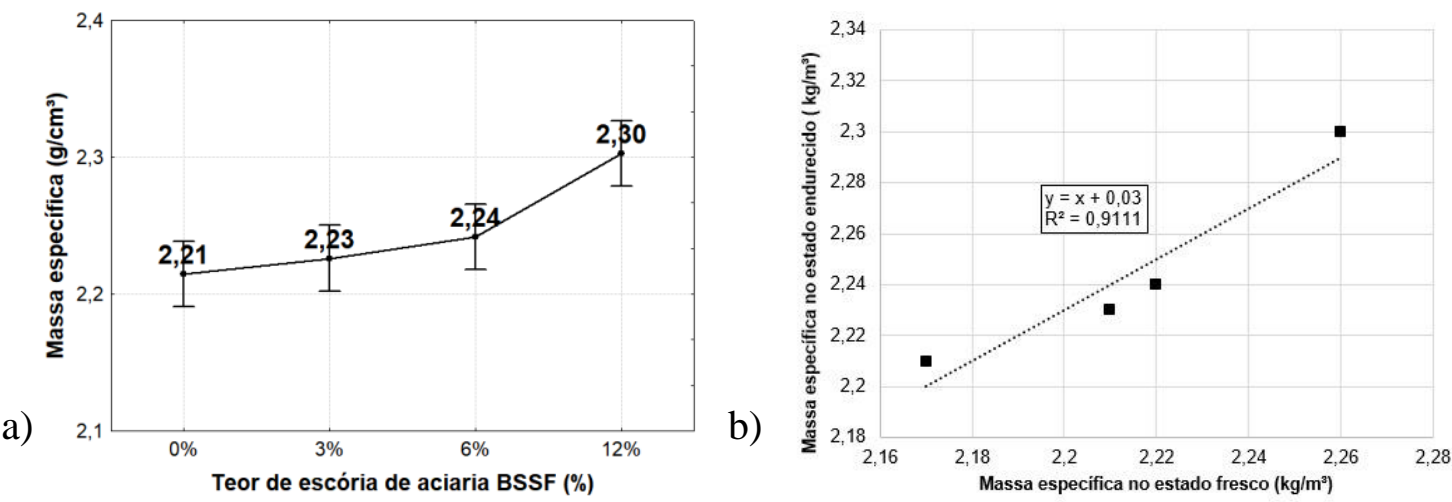

Figura 6: a) Massa específica dos concretos conforme o teor de substituição (aos 28 dias); e b) Relação entre as massas específicas do concreto nos estados fresco e endurecido.

Em relação ao ensaio de absorção de água por imersão e índice de vazios, os valores podem ser observados na Figura 7-a e 7-b, respectivamente. Verifica-se que com o aumento do teor de substituição de cimento por finos de escória de aciaria BSSF, ocasiona uma redução da absorção de água e do índice de vazios de até $35 \%$ e $33 \%$, respectivamente.
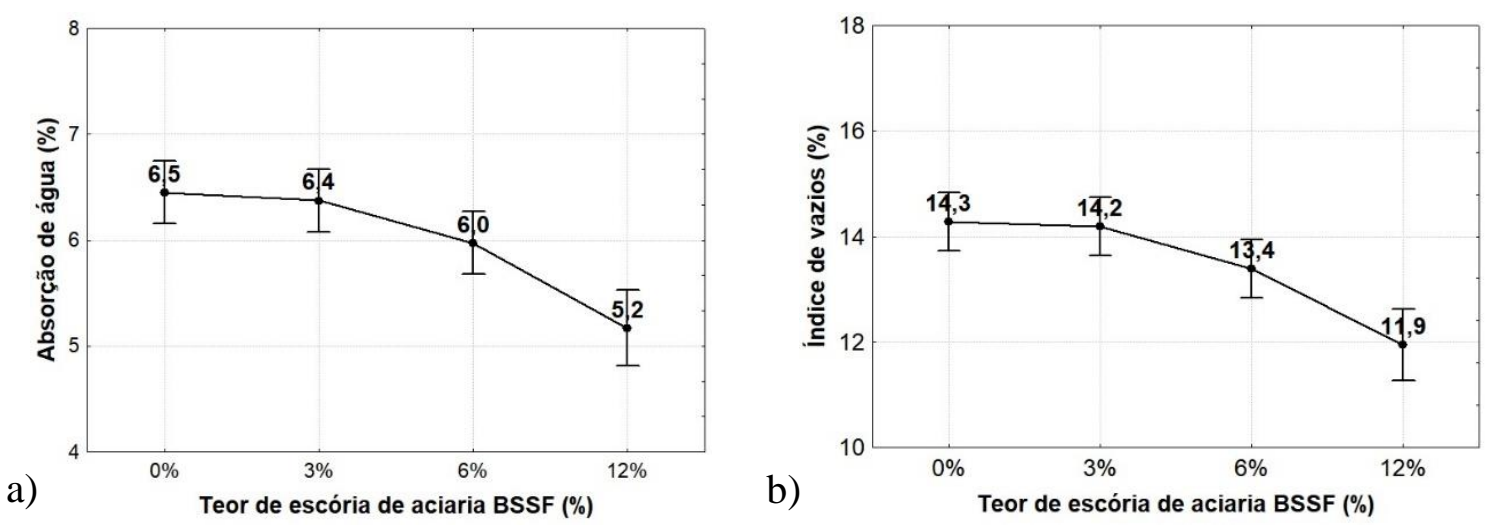

Figura 7: a) Absorção de água por imersão conforme o teor de adição (aos 28 dias); e b) índice de vazios dos concretos conforme o teor de adição de finos de escória de aciaria BSSF (aos 28 dias).

Conforme a realização da ANOVA, pode-se constatar, com nível de confiança de $95 \%$, que a redução da absorção de água e do índice de vazios é significativa. Em adição, foi possível estabelecer uma correlação entre as propriedades da absorção de água e índice de vazios com o teor de substituição de cimento por finos de escória de aciaria BSSF, sendo encontrado valores de $\mathrm{R}^{2}$ de aproximadamente 0,97 e 0,95, respectivamente para as propriedades de absorção de água e índice de vazios, conforme apresentado na Figura 8. 


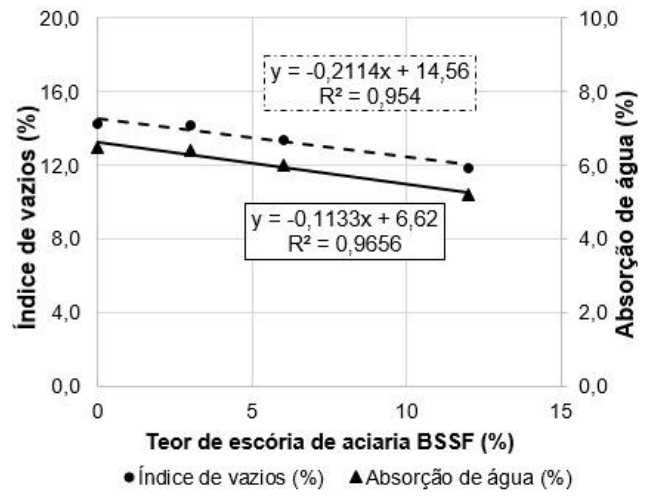

Figura 8: Correlação entre o teor de substituição do cimento por finos de escória de aciaria BSSF com o índice de vazios e a absorção de água por imersão.

As escórias de aciaria, diferentemente das escórias de alto-forno, não são capazes de reagir durante o processo de hidratação do cimento, portanto, são consideradas materiais inertes [56]. CAMPOS [59] explica que os finos inertes atuam como material de enchimento, reduzindo a quantidade de vazios no concreto. Com isto, justificam-se os resultados obtidos quanto à redução da absorção da água e índice de vazios e do aumento das propriedades mecânicas (resistência à compressão e módulo de elasticidade). No mesmo sentido, teorizam [40] que a propriedade de índice de vazios tende a diminuir à medida que se aumenta a classe de resistência do concreto, devido ao aumento da densificação da matriz. Desta forma, foi possível obter uma boa correlação entre os resultados obtidos nos ensaios de absorção de água (Figura 9-a) e do índice de vazios (Figura 9-b) com a resistência à compressão, apresentando valores de $\mathrm{R}^{2}$ aproximados de 0,84 e 0,79, respectivamente.

Quanto ao módulo de elasticidade, as correlações lineares determinadas apresentaram valores de $\mathrm{R}^{2}$ de aproximadamente 0,61 com a absorção de água (Figura 9-a) e de 0,58 com o índice de vazios (Figura 9-b). Os valores de $\mathrm{R}^{2}$ obtidos nessa relação indicam que as propriedades de absorção de água e índice de vazios apresentam uma menor relação com o módulo de elasticidade. Tal efeito pode ser explicado pelo resultado atípico obtido no traço TS6 para a propriedade de módulo de elasticidade que, apesar de não apresentar diferença significativa com o valor obtido no traço TS12, afetou de forma negativa a obtenção de uma boa correlação. Desta forma, a fim de melhorar a relação entre módulo de elasticidade e as propriedades de absorção de água e índice de vazios, faz-se necessário o estudo de novos teores de substituição, acima de $12 \%$.

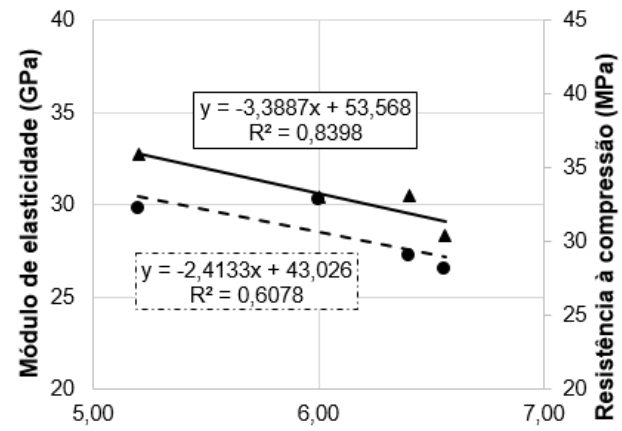

a)

$\bullet$ Módulo de elasticidade $\Delta$ Resistência à compressão

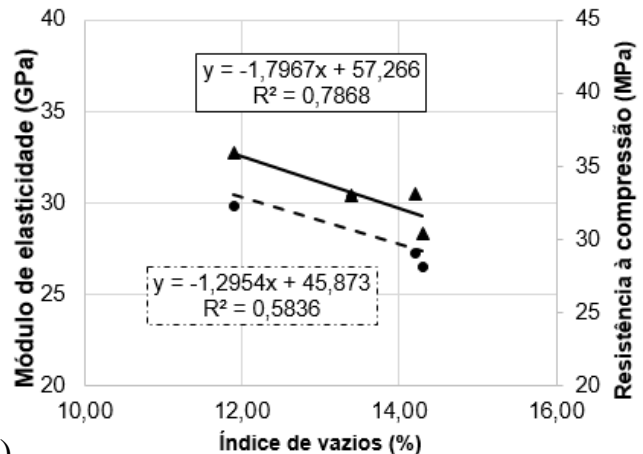

b)

Figura 9: Correlação entre o módulo de elasticidade e a resistência à compressão com: a) absorção de água; e b) índice de vazios.

\section{CONCLUSÕES}

Com base nos materiais e metodologias empregadas nesta pesquisa, obtiveram-se resultados satisfatórios quanto à substituição do cimento Portland por finos de escória de aciaria BSSF. Em relação às propriedades no estado fresco, para mesma consistência, foi possível verificar um incremento no consumo de aditivo e massa específica. Tais fatos podem ser justificados pela absorção de água, finura dos grãos, textura rugosa e elevada massa específica da escória. 
Em relação as propriedades mecânicas, o aumento do teor de substituição ocasionou um incremento na resistência à compressão e no módulo de elasticidade, sendo possível atingir valores máximos, aos 28 dias, de aproximadamente $12 \%$ e $14 \%$, respectivamente. A resistência à tração por compressão diametral não foi influenciada pela incorporação de finos de escória de aciaria BSSF.

As propriedades de absorção de água por imersão, índice de vazios e massa específica no estado endurecido foram influenciadas significativamente com a adição dos finos, conforme constatado pela ANOVA. Verificou-se uma redução de até $35 \%$ e $33 \%$, respectivamente para a absorção de água e o índice de vazios.

Por fim, recomenda-se a realização de novos ensaios com concretos de diferentes relações a/c para investigar o comportamento em concretos com outras características. Sugere-se ainda a realização de outros ensaios como resistência à abrasão e penetração de íons cloretos, no intuito de obter uma melhor caracterização dos concretos com a incorporação de finos de escória de aciaria BSSF.

\section{AGRADECIMENTOS}

Os autores agradecem ao Programa de Pós-Graduação em Engenharia Civil: Estruturas e Construção Civil (PEC) e ao Laboratório de Materiais e Construção Civil (LMCC) da Universidade Federal do Ceará - UFC. O presente trabalho foi realizado com apoio da Coordenação de Aperfeiçoamento de Pessoal de Nível Superior - Brasil (CAPES) - Código de Financiamento 001.

\section{BIBLIOGRAFIA}

[1] BERNDT, M.L., "Influence of concrete mix design on $\mathrm{CO} 2$ emissions for large wind turbine foundations", Renewable Energy, v. 83, pp. 608-614, Nov. 2015.

[2] KHOKHAR, M.I.A., ROZIERE, E., TURCRY, P., et al., "Mix design of concrete with high content of mineral additions: optimisation to improve early age strength", Cement and Concrete Composites, v. 32, pp. 377-385, Mai. 2010.

[3] RANJBAR, N., BEHNIA, A., ALSUBARI, B., et al., "Durability and mechanical properties of selfcompacting concrete incorporating palm oil fuel ash”, Journal of Cleaner Production, v. 112, pp. 723-730, Jul. 2015.

[4] GAJDA, K., BAUNE, M., THOMING, J., "Recycling Options for Steel Working Slag and Upcycling Perspectives", Procedia Manufacturing, v. 8, pp. 643-648, Dez. 2017.

[5] XIE, J., WU, S., ZHANG, L., et al., "Evaluation the deleterious potential and heating characteristics of basic oxygen furnace slag based on laboratory and in-place investigation during large-scale reutilization", Journal of Cleaner Production, v. 133, pp. 78-87, Out. 2016.

[6] PEREIRA, A.M., SILVA, C.A.R., QUEIROZ, D.C.A., et al., "Estudo das propriedades mecânicas do concreto com adição de cinza da casca de arroz", Revista Matéria, v. 20, n. 1, pp. 227-238, 2015.

[7] KANG, S.H., HONG, S.G., MOON, J., "The use of rice husk ash as reactive filler in ultra-highperformance concrete", Cement and Concrete Research, v. 115, pp. 389-400, Set. 2019.

[8] GRAUPMANN, O., MARTINS, M.A., CONSUL, M., et al., "Análise da resistência à compressão de concretos com adição de cinza de aterro sanitário”, Revista Matéria, v. 24, n.2, Jan. 2019.

[9] MORETTI, J.P., NUNES, S., SALES, A., "Self-compacting concrete incorporating sugarcane bagasse ash”, Construction and Building Materials, v. 172, pp. 635-649, Mai. 2018.

[10] TAFAREL, N.F., MACIOSKI, G., CARVALHO, K.Q., et al., "Avaliação das propriedades do concreto devido à incorporação de lodo de estação de tratamento de água”. Revista Matéria, v. 21, n. 4, pp. 974-986, Out./Dez. 2016.

[11] FERNANDEZ, L.P., MIKOWSKI, P.C.B., MACIOSKI, G., et al., “Avaliação da incorporação do lodo de estação de tratamento de água em peças de concreto intertravado”, Revista Matéria, v. 23, n. 3, Out. 2018.

[12] TIECHER, F., MANUEL, P., PAGNUSSAT, D.T., et al., “Avaliação do potencial de utilização da escória granulada de fundição em concreto autoadensável”, Ambiente Construído, v. 19, n. 1, pp. 73-88, Jan./Mar. 2019.

[13] HEIKAL, M., ZOHDY, K.M., ABDELKREEM, M., "Mechanical, microstructure and rheological characteristics of high performance self-compacting cement pastes and concrete containing ground clay bricks". Construction and Building Materials, v. 38, pp. 101-109, Jan. 2013. 
[14] LI, G., GUO, M., "Current development of slag valorisation in China", Waste Biomass Valor, v. 5, p.. 317-325, Fev. 2014.

[15] SOUZA, P.S.L., DAL MOLIN, D.C.C., PICANÇO, M.S., et al., "Avaliação do módulo de elasticidade em concreto com metacaulim de alta reatividade, proveniente de rejeito industrial", Revista Matéria, v. 20, n.4, pp. 982-99, 2015.

[16] BACARJI, E., TOLEDO FILHO, R.D., KOENDERS, E.A.B., et al., "Sustainability perspective of marble and granite residues as concrete fillers", Construction and Building Materials, v. 45, pp. 1-10, Ago. 2013.

[17] ASHISH, D.K., "Feasibility of waste marble powder in concrete as partial substitution of cement and sand amalgam for sustainable growth", Journal of Building Engineering, v. 15, pp. 236-242, Jan. 2018.

[18] VARDHAN, K., SIDDIQUE, R., GOYAL, S., "Strength, permeation and micro-structural characteristics of concrete incorporating waste marble", Construction and Building Materials, v. 203, pp. 45-55, 2019.

[19] MOOSBERG-BUSTNES, H.; LAGERBLAD, B.; FORSSBERG, E., "The function of fillers in concrete", Materials and Structures. v. 37, pp. 74-81, Mar. 2004.

[20] PATIL, K.K., WOLF, C., CHIN, S., et al., "Impact of embodied energy on materials/buildings with partial replacement of ordinary Portland cement (OPC) by natural pozzolanic volcanic ash", Journal of Cleaner Production, v. 177, p. 547-554, Dez. 2018.

[21] IABr. Relatório de Sustentabilidade. Instituto Aço Brasil, http://www.acobrasil.org.br/sustentabilidade/. Acessado em janeiro de 2019.

[22] QASRAWI, H., "The use of steel slag aggregate to enhance the mechanical properties of recycled aggregate concrete and retain the environment", Construction and Building Materials, v. 54, .p. 298-304, Mar. 2014.

[23] ETXEBERRIA, M., PACHECO, C., MENESES, J.M., et al., "Properties of concrete using metallurgical industrial by-products as aggregates", Construction and Building Materials, v. 24, n. 9, pp. 1594-1600, Set. 2010.

[24] WANG, G., WANG, Y., GAO, Z., "Use of steel slag as a granular material: Volume expansion prediction and usability criteria", Journal of Hazardous Materials, v. 184, pp. 555-560, Dez. 2010.

[25] CHEN, Z., WU, S., WEN, J., et al., "Utilization of gneiss coarse aggregate and steel slag fine aggregate in asphalt mixture", Construction and Building Materials, v. 93, pp. 911-918, Mai. 2015.

[26] TAO, G., XIAO, Y., YANG, L., et al., "Characteristics of steel slag filler and its influence on rheological properties of asphalt mortar", Construction and Building Materials, v. 201, pp. 439-446, Mar. 2019.

[27] TEO, P.T., SEMAN, A.A., BASU, P., et al., "Characterization of EAF steel slag waste: The potential green resource for ceramic Tile production”, Procedia Chemistry, v. 19, pp. 842-846, 2016.

[28] RONDI, L.R., SORLINI, S., COMINOLI, L., et al., "Concrete with EAF steel slag as aggregate: A comprehensive technical and environmental characterization", Composites Part B Engineering, v. 90, pp. 195-202, Jan. 2016.

[29] MONOSI, S., RUELLO, M.L., SANI, D., "Electric arc furnace slag as natural aggregate replacement in concrete production", Cement and Concrete Composites, v. 66, pp. 66-72, 2016

[30] ADEGOLOYE, G.; BEAUCOUR, A.L.; ORTOLA, S.; et al., "Mineralogical composition of EAF slag and stabilized AOD slag aggregates and dimensional stability of slag aggregate concretes". Construction and Building Materials. v.115, pp 171-178, Dez. 2016.

[31] BRAND, A.S., ROESLER, J.R., "Steel furnace slag aggregate expansion and hardened concrete properties", Cement and Concrete Composites, v. 60, pp. 1-9, Jul. 2015.

[32] HUANG, K.J., DENG, M., SHEN, Y.Q., et al., "Failure analysis of early age cracking of paving concrete in Donghai country", Journal Wuhan University Technology, v. 32, pp. 62-66, Mar. 2010.

[33] LIU, Y., WANG, X., "Application of the BSSF molten steel slag processing technology in POSCO", Baosteel Technical Research, v. 5, n. 2, pp. 20-23, 2011.

[34] SOUZA, T.V.P., Caracterização de escória de conversor a oxigênio obtida no processo BSSF antes e após tratamento hidrometalúrgico, Dissertação de M.Sc. PPGECMAT/UFC, Fortaleza, CE, Brasil, 2016.

[35] ASSOCIAÇÃO BRASILEIRA DE NORMAS TÉCNICAS (ABNT), NBR 15900-1: Água para amassamento do concreto - Requisitos, Rio de Janeiro, 2009. 
[36] ASSOCIAÇÃO BRASILEIRA DE NORMAS TÉCNICAS (ABNT), NBR 7211: Agregado para concreto - Especificação, Rio de Janeiro, 2009.

[37] ASSOCIAÇÃO BRASILEIRA DE NORMAS TÉCNICAS (ABNT), NBR 16605: Cimento Portland e outros materiais em pó - Determinação da massa específica, Rio de Janeiro, 2017

[38] ASSOCIAÇÃO BRASILEIRA DE NORMAS TÉCNICAS (ABNT), NBR 16697 : Cimento Portland Requisitos, Rio de Janeiro, 2018

[39] ASSOCIAÇÃO BRASILEIRA DE NORMAS TÉCNICAS (ABNT), NBR 11582: Cimento Portland Determinação da expansibilidade Le Chatelier, Rio de Janeiro, 2016

[40] MEHTA, P. K. MONTEIRO, P. J. M. Concreto: estrutura, propriedades e materiais, PINI, S. Paulo, 2014.

[41] ASSOCIAÇÃO BRASILEIRA DE NORMAS TÉCNICAS (ABNT), NBR 5752: Materiais pozolânicos - Determinação do índice de desempenho com cimento Portland aos 28 dias, Rio de Janeiro, 2014

[42] ASSOCIAÇÃO BRASILEIRA DE NORMAS TÉCNICAS (ABNT), NBR 12653: Materiais pozolânicos - Requisitos, Rio de Janeiro 2015

[43] ASSOCIAÇÃO BRASILEIRA DE NORMAS TÉCNICAS (ABNT), NBR NM 67: Concreto - Determinação da consistência pelo abatimento do tronco de cone, Rio de Janeiro, 1998.

[44] ASSOCIAÇÃO BRASILEIRA DE NORMAS TÉCNICAS (ABNT), NBR NM 47: Concreto - Determinação do teor de ar incorporado em concreto fresco - Método pressométrico, Rio de Janeiro, 2002.

[45] ASSOCIAÇÃO BRASILEIRA DE NORMAS TÉCNICAS (ABNT), NBR 9833: Concreto fresco - Determinação da massa específica, do rendimento e do teor de ar pelo método gravimétrico, Rio de Janeiro, 2008.

[46] ASSOCIAÇÃO BRASILEIRA DE NORMAS TÉCNICAS (ABNT), NBR 5738: Concreto - Procedimento para moldagem e cura de corpos de prova, Rio de Janeiro, 2015.

[47] ASSOCIAÇÃO BRASILEIRA DE NORMAS TÉCNICAS (ABNT), NBR 5739: Concreto - ensaios de compressão de corpos de prova cilíndricos, Rio de Janeiro, 2018.

[48] ASSOCIAÇÃO BRASILEIRA DE NORMAS TÉCNICAS (ABNT), NBR 8522: Concreto - determinação do módulo estático de elasticidade à compressão, Rio de Janeiro, 2017.

[49] ASSOCIAÇÃO BRASILEIRA DE NORMAS TÉCNICAS (ABNT), NBR 7222: Concreto e argamassa - Determinação da resistência à tração por compressão diametral de corpos de prova cilíndricos, Rio de Janeiro, 2011 .

[50] ASSOCIAÇÃO BRASILEIRA DE NORMAS TÉCNICAS (ABNT), NBR 9778: Argamassa e concretos endurecidos - Determinação da absorção de água, índice de vazios e massa específica, Rio de Janeiro, 2009.

[51] WESTERHOLM M., LAGERBLAD B., "Filler and filler quality of crushed rocks in concrete production", Internationalle Baustofftagung, v 2, pp. 12-15, Set. 2012.

[52] ILYUSHECHKIN, A.Y., ROBERTS, D.G., FRENCH, D., et al., IGCC Solids Disposal and Utilization, In: Final Report for ANLEC Project 5-0710-0065, CSIRO, Austrália, 2012.

[53] WINTENBORN, J.L., GREEN, J.J., Steelmaking slag: a safe and valuable product, In: The Steel Slag Coalition, National Slag Association, Washington, D.C., 1998.

[54] MOTZ, H., GEISELER, J., "Products of steel slag an opportunity to save natural resources", Waste Management, v. 21, pp. 285-293, Jun. 2001.

[55] LUXAN, M.P., SOTOLONGO, R., DORREGO, F., et al., "Characteristics of the slag produced in the fusion of scrap steel by electric arc furnace", Cement and Concrete Research, v. 30, pp. 517-519, Abr. 2000.

[56] NEVILlE, A.M., BROOKS, J.J., Propriedades do concreto. Tradução de Ruy Alberto Cremoni, 5 ed., Porto Alegre, Bookman, 2013.

[57] ASSOCIAÇÃO BRASILEIRA DE NORMAS TÉCNICAS (ABNT), NBR 6118: Projeto de estruturas de concreto - Procedimento, Rio de Janeiro, 2014.

[58] GONÇALVES, M.C. MARGARIDO, F., Ciência e Engenharia de Materiais de Construção, 1 ed., IST Press, 2012 .

[59] CAMPOS, H.F., Concreto de alta resistência utilizando pó de pedra como substituição parcial do cimento Portland: Estudo experimental, Dissertação de M.Sc., PPGECC/UFPR, Curitiba, PR, Brasil, 2015. 


\section{ORCID}

Alisson Rodrigues de Oliveira Dias Felipe Alves Amancio

Isa Lauren Ximenes de Sousa

Sarah Oliveira Lucas

Douglas Alexandre Lima

Antônio Eduardo Bezerra Cabral https://orcid.org/0000-0002-9892-6834 https://orcid.org/0000-0002-1349-683X

https://orcid.org/0000-0003-4881-3484

https://orcid.org/0000-0002-9372-9639

https://orcid.org/0000-0003-0671-4920

https://orcid.org/0000-0001-6394-1164 